\title{
RECONFIGURAÇÃO DO ACERVO DA SEÇÃO DE MEMÓRIA E ARQUIVO DO MUSEU NACIONAL APÓS O INCÊNDIO
}

\author{
Jorge Dias da Silva Junior* \\ Universidade Federal do Estado do Rio de Janeiro
}

\begin{abstract}
Resumo: Este artigo analisa a reconfiguração de acervos arquivísticos sinistrados por meio de representantes digitais do acervo original perdido, considerando o caso da Seção de Memória e Arquivo do Museu Nacional (SEMEAR), que sofreu incêndio em setembro de 2018. Desta forma, a SEMEAR perdeu-se praticamente todo o acervo. No intuito de reconstruí-lo, emergiu a ideia de reconfigurá-lo a partir de seus representantes digitais. Diante disso, surgiu o problema desta pesquisa: É possível reconfigurar acervos sinistrados a partir de representantes digitais, sob o ponto de vista da teoria arquivística clássica? Quais são as implicações teóricas e práticas? Do ponto de vista metodológico, buscou-se na literatura nacional e internacional os princípios basilares da Arquivologia. Nesse sentido, contextualiza-se os princípios da Ordem Original e da Proveniência, identificando suas características e prerrogativas. Esta pesquisa adota uma posição conceitual sobre o uso dos representantes digitais caracterizando-os como documentos de arquivo, o que possibilitará, dessa forma, a reconfiguração do acervo.

Palavras-chave: Princípios arquivísticos; representantes digitais; Museu Nacional; reconfiguração de acervo; arquivos sinistrados.
\end{abstract}

Título: RECONFIGURACIÓN DE LA COLECCIÓN DE LA SECCIÓN DE MEMORIA Y ARCHIVO DEL MUSEO NACIONAL DESPUÉS DEL INCENDIO.

Resumen: Este artículo analiza la reconfiguración de los archivos afectados por los representantes digitales de la colección original perdida, teniendo en cuenta el caso de la Sección de Memoria y Archivo del Museo Nacional (SEMEAR), que sufrió un incendio en septiembre de 2018. De esta manera, SEMEAR ha perdido prácticamente todo el acervo. Con el fin de reconstruirlo, la idea de reconfigurarlo surgió de sus representantes digitales. En vista de esto, surgió el problema de esta investigación: ¿Es posible reconfigurar colecciones siniestras de representantes digitales, desde el punto de vista de la teoría archivística clásica? ¿Cuáles son las implicaciones teóricas y prácticas? Desde el punto de vista metodológico, se buscaron los principios básicos de la archivología en la literatura nacional e internacional. En este sentido, se contextualizan los principios del orden y la procedencia originales, identificando sus características y prerrogativas. Esta investigación adopta una posición conceptual sobre el uso de representantes digitales que los caracterizan como documentos de archivo, lo que permitirá la reconfiguración de la colección.

Palabras clave: Principios de archivo; representantes digitales; Museo Nacional; reconfiguración de la colección; accidente de archivos.

Title: RECONFIGURATION OF THE COLLECTION OF THE MEMORY SECTION AND ARCHIVE OF THE NATIONAL MUSEUM AFTER THE FIRE.

Abstract: This article analyzes the reconfiguration of archives affected by digital representatives of the original collection lost, considering the case of the Memory and Archive Section of the National Museum (SEMEAR), which suffered fire in September 2018. In this way, SEMEAR has lost virtually the entire acquis. In order to rebuild it, the idea of reconfiguring it emerged from its digital representatives. In view of this, the problem of this research arose: Is it possible to reconfigure sinister collections from digital representatives, from the point of view of classical archival theory? What are the theoretical and practical implications? From the methodological point of view, the basic principles of Archiveology were sought in national and international literature. In this sense, the principles of the Original Order and Provenance are contextualized, identifying its characteristics and prerogatives. This research adopts a conceptual position on the use of digital representatives characterizing them as archiving documents, which will thus allow the reconfiguration of the collection.

Keywords: Archival principles; digital representatives; National Museum; reconfiguration of collection; files accident.

Copyright: (C) 2021 Servicio de Publicaciones de la Universidad de Murcia (Spain). Este es un artículo de acceso abierto distribuido bajo los términos de la licencia Creative Commons Reconocimiento 4.0 Internacional (CC BY 4.0).

\section{INTRODUÇÃO}

Em 02 de setembro de 2018 o Brasil foi assolado que uma perda inestimável para ciência brasileira com o incêndio do Museu Nacional.

* jorgediasjr@mn.ufrj.br

Recibido: 7-01-2021; 2 $2^{\mathrm{a}}$ versión: 28-05-2021; aceptado: 11-06-2021.

DIAS DA SILVA JUNIOR, J. Reconfiguración de la colección de la sección de memoria y archivo del Museo Nacional después del incendio. Anales de Documentación, 2021, vol. 24, nº 2. Disponible en: http://dx.doi.org/10.6018/analesdoc.462511. 
O Museu Nacional é a mais antiga instituição científica do Brasil é o maior museu de história natural e antropologia da América Latina. Foi criado por D. João VI, em 6 de junho de 1818. A Seção de Memória e Arquivo (SEMEAR), custodia a documentação histórica da instituição, que registra os primórdios da prática da ciência e propicia o entendimento da atividade científica desde as primeiras décadas do século XIX no Brasil. Antes do incêndio de 2018, seu acervo era composto de aproximadamente 3,5 milhões de itens.

Neste cenário de profunda tristeza, no dia 12 de setembro de 2018, a equipe SEMEAR e profissionais de diversas instituições criaram um grupo de trabalho para a reconstruir a seção, daí surge a ideia de reconfiguração do acervo perdido por meio de sua representação digital.

Os representantes digitais são produtos da digitalização, ou seja, são a representação, em formato de arquivo digital, de documentos originalmente não digitais.

Conforme relatado, o sinistro ocorrido no Museu Nacional ocasionou o desaparecimento quase total do acervo físico da SEMEAR. Portanto, o desaparecimento dos documentos originais, o que impossibilita a aplicação dos princípios basilares da arquivística, pois restaram apenas representantes digitais. A construção desse acervo digital fragmentado a partir de representantes digitais evidencia um enfrentamento dos princípios de Ordem Original e Proveniência, à luz da teoria arquivística, para tratamento desse acervo.

No entanto, existe o apelo da sociedade no sentido de se resgatar o acervo, tamanha a sua importância, por ajudar a contar parte representativa da história da Ciência do Brasil entre os séculos XIX e XX. Desse modo, para se recuperar o acesso a esse material, enfrenta-se a necessidade de um trabalho quase arqueológico, buscando traçar uma linha de investigação desses fragmentos, a fim de permitir a pesquisa e o acesso a informações contidas nos seus representantes digitais.

Desta forma, este artigo pretende-se acionar recursos teórico-conceituais da Arquivologia, para compreender, baseado no caso da SEMEAR, a criação de um acervo digital a partir de representantes digitais de um acervo sinistrado. Sendo assim, o problema da pesquisa pode ser explicitado por meio do seguinte questionamento:

É possível reconfigurar acervos sinistrados a partir de seus representantes digitais, sob o ponto de vista da teoria arquivística clássica? Quais são as implicações teóricas e práticas dessas ações?

Esse artigo vem apresentar parte do resultado da Dissertação de Mestrado que teve como objetivo principal elaborar recomendações para reconfiguração de acervos arquivísticos sinistrados, considerando o caso da Seção de Memória e Arquivo do Museu Nacional (SEMEAR), por meio de representantes digitais do acervo original perdido em 02/09/2018.

Para os fins desta pesquisa, a metodologia aplicada foi uma revisão de literatura visando um levantamento dos requisitos teóricos exigidos para apresentar reflexões acerca dos princípios da Proveniência e da Ordem Original, incluindo-se uma discussão sobre a teoria e a prática.

\section{ARQUIVOLIGIA NO ENFRENTAMENTEO DE UMA SITUAÇÃO DE SINISTRO}

Como visto na introdução deste trabalho, a SEMEAR sofreu um incêndio que praticamente destruiu todo seu acervo físico, restando dele apenas representantes digitais fragmentados, dispersos. Esta situação representa um desafio à pretensão arquivística de preservar os documentos dentro da ordem de seu contexto de produção.

O enfrentamento dessa questão vem ao encontro do pensamento de Brien Brothman (2018) ${ }^{1}$ quando ele diz:

Creio que os princípios, práticas e teorias arquivísticas estão sendo desafiados como jamais o foram

anteriormente. Do mesmo modo, a proliferação da tecnologia da informação e das comunicações está nos obrigando - ou deveria estar - a rever o significado de nossos princípios mais sólidos, incluindo o significado de ordem original, proveniência, documentos e arquivos. (Brothman, 2018, p. 111).

Desta forma, essa catástrofe sofrida pelo acervo da SEMEAR gerou algumas questões práticas: partindo-se da premissa de que após o incêndio não foi possível recuperar todos os documentos, nem reconstituir todas as relações, quais serão os limites e as possibilidades de reconfiguração do acervo da SEMEAR? A existência de representantes digitais de documentos perdidos permite reaver arquivos sob a ótica da Arquivologia? O que este fenômeno representa para a teoria e as práticas arquivísticas, na medida em que se recupera sob nova forma, mudando as características anteriores para permitir uma reapresentação? 
Portanto, este artigo pretende "discutir aspectos relativos à teoria da arquivística clássica e o enfrentamento prático relativo ao tratamento de acervos sinistrados". Para tanto, buscar-se-á referências teórico-conceituais da Arquivologia para encontrar respostas a estas questões.

A partir deste panorama, conduziu-se o olhar sobre a reconfiguração do acervo da SEMEAR pautado nos princípios arquivísticos, mas interagindo com as relações travadas e mantidas com o dinamismo que a situação do sinistro impõe, visando o enfrentamento da teoria com a prática arquivística.

\section{PRINCÍPIO DA PROVENIÊNCIA}

Após o citado sinistro, surgiu o questionamento acerca da possibilidade de se identificar o Princípio da Proveniência no acervo queimado. A questão então suscitada foi: como reconfigurar esse acervo levando em consideração os princípios arquivísticos? A ideia inicial era recuperá-lo a partir dos seus representantes digitais. Mas o questionamento prosseguiu: será que esse acervo digital, que será "doado" para a SEMEAR, será capaz de constituir um fundo com todos os preceitos arquivísticos, ou seja, ele respeita o princípio da proveniência? Para tentar elucidar essa questão, inicia-se pela definição desse conceito.

Na retrospectiva da criação do princípio da Proveniência, embora não seja consenso ${ }^{2}$, adota-se a data histórica de 24 de abril de 1841, em que foi formulado o princípio francês de fundo, pelo arquivista Natalys de Wally.

Para uma compreensão mais sistematizada do princípio da proveniência, apresenta-se, no quadro I, algumas definições de teóricos e dicionários da terminologia arquivística.

\begin{tabular}{|c|c|c|}
\hline Ano & Autor & Definição \\
\hline 1992 & Duchein & $\begin{array}{l}\text { O princípio da proveniência consiste em deixar agrupados, sem os misturar com outros, os } \\
\text { arquivos provenientes de uma administração, de um estabelecimento ou de uma pessoa } \\
\text { física, é o que se chama fundo de arquivo dessa administração, instituição ou pessoa, uma } \\
\text { vez que os arquivos são considerados como produto natural da atividade do organismo } \\
\text { que os gerou. }\end{array}$ \\
\hline 1998 & $\begin{array}{l}\text { Rousseau e } \\
\text { Couture }\end{array}$ & $\begin{array}{l}\text { O princípio da proveniência, de acordo com os autores, é o principio fundamental } \\
\text { segundo o qual os arquivos de uma mesma proveniência não devem ser misturados com } \\
\text { os de outra proveniência e devem ser conservados segundo a sua ordem primitiva, caso } \\
\text { exista. Os autores consideram que este princípio tem dois graus. O primeiro seria alusivo } \\
\text { ao fundo de arquivo, e o segundo, à sua organização interna. }\end{array}$ \\
\hline 2002 & Horsman & $\begin{array}{l}\text { Esse princípio pode ter uma explicação externa, ou seja, respeitar o fundo tal como foi } \\
\text { produzido, seja por um indivíduo, por um grupo ou por uma instituição como um todo. } \\
\text { Chama-se a isso de Respect des fonds. O Princípio da Proveniência também pode ser } \\
\text { aplicado internamente. }\end{array}$ \\
\hline 2006 & Bellotto & $\begin{array}{l}\text { É o mesmo que "respect des fonds", princípio fundamental da arquivística. Consiste em } \\
\text { deixar agrupados, sem misturar a outros, os arquivos (documentos de qualquer natureza) } \\
\text { provenientes de uma administração, de um estabelecimento ou de uma pessoa física ou } \\
\text { jurídica. }\end{array}$ \\
\hline 2008 & $\begin{array}{l}\text { Dicionário de } \\
\text { Biblioteconomia } \\
\text { e Arquivologia } \\
\text { (Cunha e } \\
\text { Cavalcanti) }\end{array}$ & $\begin{array}{l}\text { Princípio arquivístico fundamental, segundo o qual os documentos ou os arquivos } \\
\text { originários de uma instituição, de uma corporação, de uma família ou de uma pessoa não } \\
\text { devem ser incorporados a documentos ou arquivos de outras proveniências; inclui, às } \\
\text { vezes, o princípio do respeito à ordem original; princípio do respeito aos fundos; e } \\
\text { respeito aos fundos. }\end{array}$ \\
\hline 2015 & $\begin{array}{l}\text { Dibrate } \\
\text { (CONARQ) }\end{array}$ & $\begin{array}{l}\text { Princípio segundo o qual os arquivos originários de uma instituição ou de uma pessoa } \\
\text { devem manter sua individualidade, não sendo misturados aos de origem diversa. }\end{array}$ \\
\hline
\end{tabular}

Quadro I. Definições relativas ao Princípio da Proveniência. Fonte: Elaborado pelo autor (2019), com base nos autores citados. 
Segundo as definições apresentadas no quadro I, pode-se verificar que o princípio da proveniência consiste em não misturar documentos oriundos de fundos distintos, para que sejam mantidas as relações orgânicas existentes nos conjuntos documentais.

Esta premissa do princípio da proveniência leva ao seguinte questionamento: “é possível identificá-lo no acervo sinistrado, ou melhor dizendo, visualizá-lo na reconfiguração do acervo da SEMEAR através do recebimento de representantes digitais dos pesquisadores?"

No processo de recebimento desses representantes digitais, a principal questão é precisar a qual fundo eles pertenciam. Essa identificação da proveniência se configura como uma tarefa complexa, porque, mesmo sendo realizada por equipe de verificação especializada, existem vários fatores que podem dificultar essa delimitação. Primeiro, as informações sobre a documentação doada pelo usuário, visto que podem existir dados imprecisos e incorretos; a baixa resolução da imagem pode comprometer visualização; ou ainda, faltar informação no próprio documento. Essas são algumas particularidades que demonstram a dificuldade, na prática, de se direcionar ao fundo correto cada documento doado. Portanto, nessa doação do documento digital, que por sua vez, é uma cópia do documento que a instituição custodiava, vai se forma é um acervo novo que irá recompor as informações do acervo perdido.

Outro fator pertinente a ser observado é o fato de que os diversos fundos que faziam parte do acervo que conversavam entre si, ou seja, eles tinham assuntos em comum, tanto no acervo administrativo quanto nos arquivos pessoais. Por essa incapacidade de precisão na análise baseada somente no conteúdo do documento, faz-se necessário modificar o olhar para a aplicação do princípio, levando em conta o contexto de produção utilizado pelo pesquisador. $\mathrm{O}$ produto que resultou do uso dos documentos pode revelar alguns dados que talvez ajudem a determinar o fundo correto. Assim, a montagem desse quebra-cabeças torna-se uma tarefa quase "arqueológica".

Terry Cook (2018) salienta que o princípio da proveniência não é mas visto como método de organizar documentos, mas sim como um construto intelectual criado por meio da análise das variadas relações existentes entre os documentos, seus criadores e suas funções.

Portanto, diante das novas tecnologias disponíveis, é preciso buscar respostas sobre como lidar com esses fundos abertos e com crescente fluidez e complexidade de processamento arquivístico, nesta era digital. Quando aponto, fundos abertos trato da constante repasse ou descoberta de documentos digitais de documentos que faziam parte do acervo queimado, sendo assim esses fundos sempre poderão receber novos documentos. Nesse contexto, tenta-se analisar o que dizem os teóricos da área sobre o princípio da proveniência em documentos eletrônicos.

Segundo Cook (2018), as grandes modificações na narrativa da arquivologia neste século mostram que é preciso reconhecer esses padrões de mudança no próprio discurso e debater as questões pertinentes e suas implicações para as metodologias e estratégias arquivísticas e, finalmente, incorporar os resultados à prática cotidiana. $\mathrm{O}$ autor aponta que os arquivos passaram de uma justificativa jurídico-administrativa, baseada em conceitos de caráter estatal, para uma justificativa sociocultural, baseada nas políticas públicas e no uso público.

Já Natália Tognoli afirma a “obsolescência dos princípios e métodos arquivísticos gerados no século XIX, defendendo seu repensar para a sobrevivência e adaptação da disciplina nos dias atuais" (TOGNOLI, 2010, p. 69). Considerando que o protagonismo das novas tecnologias da informação, os meios de comunicação, as formas de produção documental, a diversidade de suportes, a globalização e as demandas sociais são reflexos da realidade contemporânea.

Para Charles Dollar, ninguém ficará imune ao poder da tecnologia da informação, e isso vai atingir os princípios e práticas de arquivo. Em relação à proveniência, o autor diz que:

“[...] os documentos em papel trazem geralmente consigo a informação relacionada com a proveniência, a adesão a esse princípio tem sido franca e direta para a maior parte dos documentos arquivísticos. Isso não é verdadeiro quanto aos registros eletrônicos" (DOLLAR, 2012, p. 10). E afirma ainda que “[...] é impossível afirmar a proveniência de documentos eletrônicos usando-se as abordagens tradicionais” (DOLLAR, 2012, p. 10).

Acerca dessas afirmações, pode-se notar que o princípio da proveniência precisa passar por uma adaptação frente às novas demandas do universo digital. Nesse contexto, Cook (2018, p. 45) aponta para uma "nova" proveniência, 
com olhar mais funcional do que estrutural, em decorrência da mutabilidade das organizações nos dias atuais, uma proveniência, em que o foco é o contexto da produção de documentos.

A se referir a esse momento, Tognoli enfatiza que novos contextos e desafios despertam um olhar distinto sobre o princípio da proveniência, focando no conhecimento da forma (o como) e no motivo pelo qual o documento foi produzido (o porquê), passando-se a ter como referência a avaliação dos "processos e contextos de criação dos documentos e as relações dos usuários com os criadores dos documentos” (TOGNOLI, 2010, p. 13).

Além disso, Monks-Lesson (2011) investigou se o princípio da proveniência é reinterpretado de modo a criar novos e flexíveis contextos ou se este atua de forma diferente nos arquivos eletrônicos. A autora verificou que os arquivos de modo geral não se baseiam tanto na origem dos documentos, mas sim na maneira como estes podem estar relacionados a uma ideia central ou pessoa, concluindo, ainda, que:

[...] assim como documentos podem assumir novos significados e contextos, os entendimentos da proveniência podem mudar de forma a abranger não somente os contextos originais de criação (que devem ser preservados), mas também aos novos contextos a que os documentos possam vir a pertencer. (MONKSLESSON, 2011, p. 56).

A tecnologia reporta-se ao conhecimento, ou seja, volta a atenção para a "proveniência", o respeito aos fundos, ao contexto e à ordem original dos documentos, o centro teórico da Arquivologia. Essa ideia preconiza que a base deste princípio esteja centrada no contexto de sua produção, ou seja, na configuração e na finalidade dos documentos.

Segundo Cook (2018), nessas análises a respeito do princípio da proveniência destaca-se a contribuição dos australianos, que apresentaram uma reinterpretação da proveniência através de Peter Scott. Ao invés de se concentrar nas indagações pertencentes à avaliação dos documentos eletrônicos, esse autor focalizou na sua descrição. Scott (1966 apud COOK, 2018) propõe um "Sistema de Séries" (series system), em que não se valoriza mais o órgão ou estrutura administrativa, e sim a função desenvolvida. Logo, perde-se a noção de ligar um fundo à sua proveniência, surgindo também a noção de múltiplas proveniências, o que evidencia as inter-relações entre os mais diversos produtores e documentos.

Scott (1966) assinala que o conceito de record group ${ }^{3}$ limita a gestão de arquivos e é uma complicação desnecessária. Segundo o autor, a adoção do series system evita todas as dificuldades ocasionadas pelo arranjo físico e permite o estabelecimento de relacionamentos mais eficientes entre os documentos e seu contexto de criação (SCOTT, 1966 apud COOK, 2018, p. 55).

A grande variedade de funções e a complexidade dos laços de hierarquia nos diversos níveis das instituições ocasionam um problema na definição do fundo. Dessa forma, o sistema de séries foi a maneira encontrada pelos australianos para evidenciar o complexo contexto de criação dos documentos e, nesse ambiente complexo, surge o princípio da proveniência.

Jennifer Douglas ${ }^{4}$, ao citar o modelo australiano, afirma que o "Sistema de Séries" redefine a proveniência como uma rede de relações entre "entidades" arquivísticas e "entidades" de contexto, estas últimas incluindo aquelas que criam, usam e acumulam documentos e as funções das quais estes resultam. De maneira semelhante, essa nova visão de proveniência como sistema de relações de muito com muitos está sancionada no ISAD $(\mathrm{G})$ : General International Standart Archival Descreption (em português, Norma Geral Internacional de Descrição Arquivística), que define a proveniência como: "A relação entre os documentos e a organização ou indivíduos que os criaram, acumularam e/ou mantiveram e os utilizaram na condução de atividades pessoais ou corporativas” (DOUGLAS, 2016, p. 58).

Um segundo efeito, a ser observado, do princípio da proveniência ou respeito aos fundos, é a concepção de totalidade. Nesse sentido, Hilary Jenkinson, no seu Manual de Administração de Arquivos, defendia que o fundo podia ser definido como:

[...] o conjunto dos arquivos resultantes do trabalho de uma administração - qualquer que seja a escala da mesma - constituindo um todo orgânico, completo por si mesmo, capaz de tratar de forma independente, sem a intervenção de uma autoridade superior ou exterior, todos os aspectos dos assuntos que são da sua competência. (JENKINSON, 1937 apud BELLOTTO, 2006, p. 129).

Porém, essa visão traz uma noção de totalidade, de que todos os documentos produzidos por aquela instituição ou pessoa estão contidos nesse fundo. Essa ideia esbarra em alguns problemas práticos. Millar (2015) argumenta que 
nenhum arquivo tem, terá ou já teve "a totalidade dos documentos" de qualquer produtor. Documentos são destruídos, perdidos, transferidos ou modificados antes mesmo de chegarem aos arquivos. Uma vez em custódia, eles podem ser escolhidos, selecionados ou removidos (MILLAR, 2015, p. 150). A autora continua seu questionamento: "se os fundos são formados por fragmentos, então qual seria a lógica de atribuir um título que identifica um fragmento como um todo?"

Porém, ao se analisar o Manual dos Holandeses, escrito por Muller, Feith e Fruin (1973), fica demonstrado que um fundo pode ser constituído de um único item ou um pequeno agrupamento de itens. Se o que restou é apenas isso, é disso que se constitui o fundo.

Para equacionar essa questão, Millar (2015) propõe uma solução simples: redefinir o conceito de fundo. Em vez de definir fundo como a totalidade dos documentos criados, acumulados ou utilizados por alguém, basta defini-lo como resquícios, fragmentos conservados (MILLAR, 2015, p. 151).

Além disso, a autora sugere que, em vez de simular a posse dos fundos, deve-se explicar o que ele realmente contém, sugerindo assim uma redefinição do princípio da proveniência, que deveria englobar três componentes relacionados:

O primeiro deve ser a história do produtor, a história de quem produziu, acumulou e utilizou os documentos ao longo do tempo. [...] O segundo componente de proveniência deve ser a história dos arquivos ou a trajetória da gestão física e do movimento dos documentos ao longo do tempo [...]. O terceiro componente de proveniência deve ser a história arquivística ou a explicação da transferência de propriedade ou custódia dos arquivos do produtor ou custodiador para a instituição arquivística e o subsequente cuidado desses documentos [...] (MILLAR, 2015, p. 158).

Essa nova abordagem do princípio da proveniência, ou de respeito aos fundos, questiona o seu caráter de totalidade. É preciso fazer um exercício de revisão, dada a evolução das questões de definição terminológica da arquivística. Essa visão de Millar (2015) traz uma análise que pode não ser um consenso na área, mas optou-se por trazê-la à tona, porque remete diretamente ao problema de pesquisa, uma vez que o acervo da SEMEAR terá "fundos" formados por fragmentos, pois, ainda que ocorra um volumoso envio de documentos por parte dos pesquisadores, não será possível recuperar a totalidade do acervo queimado. Esse novo acervo terá um caráter informativo. Portanto, essa premissa de que o conceito pode ser atribuído a todo o material recebido permite uma argumentação teórica sobre a possibilidade de se atribuir o título de fundo a esse novo acervo que será formado.

Diante de todas essas mudanças criadas pelos documentos eletrônicos, Cook apresenta o seguinte questionamento:

Como fica a proveniência nos documentos eletrônicos? Os documentos eletrônicos, como pensava inicialmente Peter Scott, trazem os arquivistas para a era dos arquivos e documentos virtuais, na qual o documento físico e seu arranjo, tão fundamentais para o discurso arquivístico tradicional neste século, têm hoje importância secundária, em comparação com o contexto funcional em que o documento é criado e descrito por seu produtor e utilizado por seus contemporâneos. (COOK, 2018, p. 59).

E diante dos vários problemas criados pelos documentos eletrônicos, Bearman (1990) conclui que:

Até agora a análise enriqueceu o conceito de proveniência e reforçou sua ligação direta com as missões, funções e até mesmo as atividades e transações de determinada organização, e não com as unidades organizacionais [...]. Os documentos eletrônicos impõem aos arquivistas esse duro desafio: os princípios básicos da arquivologia somente serão preservados se descartarmos muitas de suas tradicionais interpretações e aplicações práticas. (BEARMAN, 1990 apud COOK, 2018, p. 60-61).

Diante disso, Millar (2015) argumenta que é preciso saber que a realidade intelectual da proveniência e a realidade física dos arquivos não são equivalentes. Um conjunto de documentos pode derivar de diversos produtores e um produtor pode depositar documentos em diversos lugares físicos. Proveniência e fundo não são a mesma coisa e tampouco representam uma relação constante, de um para um (MILLAR, 2015, p. 148).

E de acordo com o modelo australiano, segundo Cook:

Tais inter-relações não são relações fixas, de um para um, como nas abordagens arquivísticas tradicionais de arranjo e descrição; elas são, antes, relações de muitos-para-um, um-para-muitos e muitos-para-muitos: são, por exemplo, relações entre várias séries e um criador, entre vários criadores e uma série, entre muitos criadores e muitas séries, entre criadores e outros criadores, entre séries e outras séries e entre séries e 
criadores para funções e vice-versa, entre funções correntes e suas predecessoras ou sucessoras, entre agências mais antigas e documentos de suas sucessoras - uma infinita riqueza de quase todo tipo concebivel de inter-relacionamento contextual entre documentos, criadores e funções. (COOK, 1998, p. 7, tradução nossa).

Essa afirmação vai ao encontro da reconfiguração da SEMEAR, que vai receber documentos de diversos pesquisadores, ou seja, esse acervo será composto de diversos doadores, pois cada um enviará documentos pertencentes à sua pesquisa e que podem fazer parte da reconfiguração de um ou mais fundos. Quando se tratar de documentos arquivísticos digitais, deve-se considerar o contexto de criação do documento e não somente o seu local de origem.

As grandes modificações no discurso da Arquivologia neste século mostram que é preciso reconhecer esses padrões de mudanças dentro do próprio discurso e debater as questões pertinentes e as implicações para as metodologias e estratégias arquivísticas, e finalmente, incorporar os resultados desse debate à prática cotidiana.

A teoria arquivística inspira-se agora na análise dos processos de produção de documentos, e não no arranjo e descrição dos produtos documentados em arquivos. Como conclui Eric Ketelaar ${ }^{5}$ :

[...] a arquivologia funcional substitui a arquivologia descritiva, [...] somente por meio de uma interpretação funcional do contexto em que se insere a produção de documentos, é possível compreender a integridade do fonds e as funções dos documentos arquivísticos em seu contexto original [...]. (KETELLAR, 1996 apud COOK, 2018, p. 65).

Nesse contexto, Cook (2018) salienta que o próprio documento não mais será concebido como uma peça única, de um meio documental que integra a estrutura, o conteúdo e o contexto da informação num lugar físico, e sim como uma combinação virtual de várias partes dispersas reunidas (em diversos softwares de controle e processos transacionais) para executar ou fornecer comprovação de uma transação ou ideia.

Analogamente, o fundo arquivístico não mais deverá refletir uma ordem física estática, baseada em regras decorrentes da transferência, arranjo ou acumulação de documentos, e sim um caráter dinâmico da produção múltipla e de autoria múltipla, com foco na função e na atividade, captando, assim, com maior precisão, a contextualidade dos documentos no mundo moderno. Dessa forma, a Arquivologia não deve ser vista como um conjunto de leis científicas imutáveis, abnegadamente formuladas e tidas como válidas para sempre. O reconhecimento da natureza cambiante da Arquivologia ao longo do tempo torna-se uma força positiva dessa disciplina, e não negativa.

Bucci (1992) afirma que os princípios arquivísticos não são definitivos, mas, assim como os conceitos da própria história, da literatura ou da filosofia, refletem o espírito de sua época, sendo, portanto, reinterpretados pelas gerações seguintes (BUCCI, 1992 apud COOK, 2018, p. 31).

Para sintetizar os pensamentos apresentados a respeito do princípio da Proveniência no processo de reconfiguração do acervo, elaborou-se o quadro II, a partir das contribuições da literatura apresentada. 


\begin{tabular}{|c|c|c|}
\hline Ano & Autor & $\begin{array}{l}\text { Contribuição ao processo de Reconfiguração do Acervo sob o aspecto do } \\
\text { Princípio da Proveniência }\end{array}$ \\
\hline 1989 & Dollar, C. & $\begin{array}{l}\text { Afirma que documentos em papel geralmente trazem consigo a informação } \\
\text { relacionada à proveniência, mas é impossível constatar a proveniência de } \\
\text { documentos em ambiente digital por meio do uso de abordagens tradicionais. }\end{array}$ \\
\hline 1998 & Ducrot, A. & $\begin{array}{l}\text { Propõe uma revisão do princípio da Proveniência, uma abordagem aberta e } \\
\text { lacunar na reconstituição dos fundos. O acervo teria inúmeras proveniências e } \\
\text { estaria aberto e sempre em reconstituição. A teoria está sendo confrontada com } \\
\text { a prática, devido à possibilidade de alteração do ambiente de manutenção, uso e } \\
\text { produção de documentos. }\end{array}$ \\
\hline 2002 & Millar, L. & $\begin{array}{l}\text { Afirma a impossibilidade de um fundo conter a totalidade dos documentos. } \\
\text { Propõe a redefinição do conceito de fundo: em vez de defini-lo como a } \\
\text { totalidade dos documentos criados, acumulados ou utilizados por alguém, basta } \\
\text { defini-los como resquícios, fragmentos conservados. }\end{array}$ \\
\hline 2011 & $\begin{array}{l}\text { Monks-Lesson, } \\
\text { E. }\end{array}$ & $\begin{array}{l}\text { Verificou que os arquivos se baseiam mais na maneira como estão relacionados } \\
\text { a uma ideia central ou pessoa, do que na sua origem. Documentos podem } \\
\text { assumir novos significados e contextos, e a proveniência deveria abranger tanto } \\
\text { os contextos originais de sua criação, que devem ser preservados, como os } \\
\text { novos contextos a que eles possam vir a pertencer. }\end{array}$ \\
\hline 2018 & Bearman, D. & $\begin{array}{l}\text { Ao analisar os problemas e desafios dos documentos eletrônicos, o autor propôs } \\
\text { o descarte das interpretações tradicionais e aplicações práticas dos princípios } \\
\text { básicos da Arquivologia. }\end{array}$ \\
\hline 2018 & Cook, T. & $\begin{array}{l}\text { Propõe uma nova Proveniência, com uma visão mais funcional do que } \\
\text { estrutural, de acordo com o contexto da produção dos documentos. O princípio } \\
\text { da proveniência não é mais visto como método de organizar documentos, mas } \\
\text { construído por meio da análise das variadas relações existentes entre os } \\
\text { documentos, seus criadores e suas funções. }\end{array}$ \\
\hline
\end{tabular}

Quadro II. Contribuições do Princípio da Proveniência na reconfiguração do acervo. Fonte: Elaborado pelo autor (2019), com base nos autores citados.

Depois de se compreender o surgimento, a consolidação, as críticas ao princípio da proveniência e as abordagens de alguns teóricos, iremos ver analisar o princípio da Ordem Original.

\section{PRINCÍPIO DA ORDEM ORIGINAL}

Assim como o princípio da Proveniência, a Ordem Original também é um dos princípios basilares da Arquivologia. Ela se vincula significativamente ao princípio da proveniência. Para Rousseau e Couture (1998, p. 83), essa vinculação é representada, inclusive, na denominação adotada para os dois princípios: primeiro grau do princípio da proveniência e segundo grau do princípio da Ordem Original. Este último visa o respeito ou a reconstituição da ordem interna do fundo.

Um questionamento recorrente sobre a Ordem Original é sobre como enquadrá-la: ela seria um princípio ou uma característica do princípio da proveniência? Sobre essa questão, Sousa chegou à conclusão de que o princípio da ordem original "não é ponto pacífico na literatura arquivística" (SOUSA, 2003, p. 242). Diante da ausência de um consenso que classifique a ordem original como característica ou princípio, recorreu-se aos dicionários de terminologia e teóricos da área para buscar as abordagens sobre o tema. Diante desse panorama, elaborou-se o quadro III, com o objetivo de demonstrar como é definido o princípio da ordem original. 


\begin{tabular}{|c|c|c|}
\hline Ano & Autor & Definição \\
\hline 1982 & Duchein & $\begin{array}{l}\text { Todos os documentos que provêm de um corpo, um estabelecimento, uma família } \\
\text { ou um indivíduo formam um fundo e devem permanecer unidos. Manter a ordem } \\
\text { original como princípio de respeito à estrutura dos fundos. }\end{array}$ \\
\hline 1996 & $\begin{array}{l}\text { Dicionário de } \\
\text { Terminologia } \\
\text { Arquivística }\end{array}$ & $\begin{array}{c}\text { Princípio que, levando em conta as relações estruturais e funcionais que presidem } \\
\text { a gênese dos arquivos, garante sua organicidade. }\end{array}$ \\
\hline 1998 & $\begin{array}{l}\text { Rousseau e } \\
\text { Couture }\end{array}$ & $\begin{array}{l}\text { Caracterizam a Ordem Original como o segundo grau do Princípio da Proveniência. } \\
\text { A Ordem Original visa o respeito ou a reconstituição da ordem interna do fundo. }\end{array}$ \\
\hline 2005 & DIBRATE & $\begin{array}{l}\text { Princípio segundo o qual o arquivo deveria conservar o arranjo dado pela entidade } \\
\text { coletiva, pessoa ou família que o produziu. }\end{array}$ \\
\hline 2006 & Bellotto & $\begin{array}{l}\text { Considera a Ordem Original como um desdobramento do Princípio da Proveniência } \\
\text { Também é chamada de Princípio da Santidade. }\end{array}$ \\
\hline 2008 & $\begin{array}{l}\text { Dicionário de } \\
\text { Biblioteconomia } \\
\text { e Arquivologia }\end{array}$ & $\begin{array}{l}\text { Princípio arquivístico fundamental, segundo o qual os arquivos que procedem, isto } \\
\text { é, que provêm de uma mesma origem, devem manter o mesmo arranjo (ou } \\
\text { ordenação) estabelecido pelo órgão de origem. }\end{array}$ \\
\hline
\end{tabular}

Quadro III. Definições relativas ao Princípio da Ordem Original. Fonte: Elaborado pelo autor (2019), com base nos autores citados.

Ao examinar as abordagens apresentadas no quadro III, notou-se uma disparidade entre o apresentado em dicionários de terminologia e o enunciado por teóricos da área. Isto porque o princípio de respeito à ordem original ora é tratado como princípio independente do princípio da proveniência, ora é tratado como um desdobramento desse princípio. Porém, a maioria dos autores corrobora a ideia de que a ordem original é um desdobramento do princípio da proveniência:

Há um primeiro grau do princípio da proveniência que permite isolar e circunscrever a entidade que constitui um fundo de arquivo no que diz respeito ao modo como este se distingue de qualquer outro. Além disso, há um segundo grau, que visa o respeito ou a reconstituição da ordem interna do fundo. (ROUSSEAU; COUTURE, 1998, p. 83).

Nesse sentido, para esta pesquisa foram selecionados três dicionários terminológicos, produzidos no Brasil, de muita representatividade em trabalhos da área. A análise dos manuais ofereceu subsídios a este estudo para concluir que as definições do Princípio de Respeito à Ordem Original, de maneira geral, apontam para a importância da manutenção do arranjo dado pelo produtor dos documentos.

A respeito dos dicionários, Rangel (2015) considera que são fontes importantes para o desenvolvimento de qualquer área, logo, os dicionários deveriam ser fruto de apurada pesquisa. Nota-se que ao analisar os dicionários na maioria dos casos, não é possível identificar os critérios que justificam a seleção dos termos nos próprios dicionários e sequer nas obras dos teóricos.

Sendo assim, é preciso refletir sobre quais seriam os critérios adotados para a confecção desses instrumentos, uma vez que estes não estão especificados.

Nesse contexto, Brothman pergunta: o que representa o conceito de ordem original? O autor afirma que a ordem original representa capturar a parte objetiva do passado, tornando-o presente uma vez mais. Porém, ao menos em termos estritos, existem limites para a capacidade de se preservar a ordem original (BROTHMAN, 2018, p. 93).

Esses impedimentos ficam evidentes nas seguintes situações: primeiro, quando se remove os documentos de seu lugar original de proveniência para colocá-los em arquivos. Segundo, uma vez transferidos esses documentos, a organização arquivística também deturpa necessariamente a ordem original de modos mais sutis. Além disso, quando se decide por destruir documentos que faziam parte de um arquivo, perde-se a ordem original.

Healther Beattie (2007) ${ }^{6}$ observa que o "documento que chega a um arquivo permanente não é necessariamente o mesmo quando sai da produção original” e descreve as diversas intervenções editoriais e censorais realizadas por 
subsequentes detentores ou guardas dos originais e que afetarão a compreensão desses documentos no futuro. (BEATTIE, 2007 apud DOUGLAS, 2016, p. 64).

Brothman afirma que, quando se realiza o processo para aplicação da ordem arquivística prática, idealizada, intelectual, ao invés de ordem original, cria-se uma ordem arquivística. Convém, pois, estabelecer uma distinção, ao menos conceitual, entre ordem original e ordem arquivística. Dessa forma, é preciso questionar a respeito da manutenção da ordem original durante o tempo, ainda mais nos arquivos modernos, em que as origens nunca são definitivas (BROTHMAN, 2018, p. 100).

Para Tom Nesmith ${ }^{7}$ talvez seja o caso de se reportar não a uma ordem original, mas à ordem em que os documentos são recebidos por um arquivo. E se os documentos estiverem de tal modo desordenados ao serem recebidos, que requeiram sua reorganização pelos arquivos, a ordem em que serão colocados provavelmente não será também a original (NESMITH, 2018, p. 161).

Observa-se aqui um questionamento frente a essa possibilidade de realmente existir uma "ordem original" nos arquivos, pelo menos dentro da visão clássica. As novas tecnologias sugerem uma nova concepção e apontam uma incompatibilidade da prática arquivística com a teoria. Por isso, é preciso revisar esse conceito, tornando-o mais abrangente e alinhado com a prática, visto a necessidade de adequar-se às novas tecnologias. Nesse contexto se enquadra a reconfiguração do acervo da SEMEAR, pois a entrada dos documentos no arquivo será realizada de modo aberto, e assim, com várias "proveniências", ou seja, vários doadores, a ordem original, nesse novo acervo, será a ordem de entrada dos documentos no arquivo.

Durante esta pesquisa, percebeu-se também a necessidade de buscar compreender como se configura o princípio da ordem original a partir dos documentos pessoais, tendo em vista que, em grande parte do acervo da SEMEAR era composta de fundos de cientistas. Na busca por respostas a esta questão, encontrou-se a seguinte consideração de Ariane Ducrot:

[...] o princípio da proveniência recebe uma aplicação particular, já que os documentos são reagrupados, não em função de sua origem (proprietário), mas do autor do fundo. Classificam-se em um mesmo fundo, por exemplo, os arquivos de um politico doados por seus filhos e por seus colaboradores, indicando-se claramente no inventário as diferentes origens. Esse princípio é violado com bastante frequência na medida em que é admitido reagrupar em um mesmo fundo tanto os documentos recebidos por seu autor, quanto os originais que ele tenha enviado a terceiros e que, normalmente, pertenceriam aos fundos eventualmente constituídos por esses terceiros. (DUCROT, 1998, p. 162).

Diante dessas ponderações, avalia-se que a teoria clássica dos princípios da proveniência e da ordem original possui lacunas em relação à prática arquivística em documentos pessoais. A reconfiguração da SEMEAR vem ao encontro das ponderações de Ducrot, segundo as quais o acervo, estará aberto e sempre em reconstituição. Dessa forma, esses princípios precisam de uma revisão. Principalmente quando trata de arquivos pessoais e documentos arquivísticos digitais, essa teoria está sendo confrontada pela prática, devido à possibilidade de alteração do ambiente de manutenção, uso e produção de documentos.

Jennifer Meehan $^{8}$ (2018) critica o conceito clássico de ordem original, devido à incapacidade de se "reconstituir a ordem original" dos documentos desde sua gestão. Porém, a maior limitação talvez seja o fato de o conceito arquivístico de ordem original nada dizer a respeito do que fazer com, ou mesmo de como considerar os documentos que não apresentam uma ordem coerente e discernível, como quase sempre é o caso dos documentos pessoais.

Mesmo que o enfoque da autora seja verificar a aplicabilidade do conceito da ordem original a documentos pessoais, essa reflexão também pode ser aplicada aos documentos administrativos e eletrônicos, uma vez que a manutenção "fiel" da ordem original dos documentos advindos da gestão, sejam eles de qualquer tipo e formato, apresenta certas limitações, sendo mais plausível adotar a ordem em que eles entram no arquivo.

Meehan (2018) justifica essa posição pelo fato de haver diferenças entre o modo como os documentos pessoais são criados, utilizados e guardados inicialmente e ao longo do tempo pelo produtor ("custódia pessoal"); o modo como os documentos são utilizados, guardados e transmitidos por custodiantes ulteriores ("história custodial"); e o modo como os documentos são tratados quando confiados à custódia arquivística, antes mesmo de serem formalmente processados ("intervenção arquivística"). A autora afirma ainda que o atual conceito de ordem original utiliza uma abordagem do particular para o geral, a fim de interpretar e preservar as relações existentes entre os documentos. Para equacionar essa questão, ela sugere uma reconceituação da ordem original: 
[...] onde o processo analítico é, ou pode ser, multidirecional, partindo do geral para o particular, do que se sabe sobre o contexto para o que não se sabe sobre o modo como o produtor ou os custodiantes ulteriores organizaram ou adaptaram os documentos; ou, então, horizontalmente, partindo do que se sabe sobre o contexto funcional (como o produtor criou os documentos) para o que não se sabe sobre outras contextualidades (história custodial e intervenções arquivísticas); ou, ainda, partindo de fora para dentro, do que se sabe sobre a história dos documentos para o que não se sabe sobre a função de certo formato de documento em determinado fundo. (MEEHAN, 2018, p. 325).

Esse entendimento do conceito remete a abordar o princípio da ordem original como esquema conceitual, decompondo-se as atividades do produtor em seus processos constitutivos (ou seja, uma análise funcional) e focalizando-se nas intenções (ou objetivos, propósitos, desígnios) do produtor, tal como são concebidas. Usar a ordem original como esquema conceitual possibilita abordar essas questões de maneira a esclarecer não só as relações entre os documentos e as atividades do produtor, mas também importantes aspectos do contexto funcional.

Em vez de obscurecer o contexto original dos documentos, os fatores ligados à história custodial (ou à sua preservação, utilização e transmissão pelos custodiantes) incluem parte das várias contextualidades que possibilitam conhecer tais documentos em seus próprios termos (MACNEIL, 2008 apud MEEHAN, 2018, p. 321). Além disso, ao realizar essa análise buscando esclarecer certos aspectos da história custodial, o autor pretende identificar as intervenções feitas por outros que não o produtor (por exemplo, as ordens que o custodiante tenha talvez estabelecido ao preparar o fundo para doá-lo a uma instituição arquivística). Isso significa começar a reconhecer a importância do contexto arquivístico (ou seja, o que acontece com os documentos sob custódia arquivística e a relação entre o arquivista e tais documentos) para compreender os documentos em seus próprios termos.

O importante nesse exercício especulativo é não tentar restabelecer a ordem do produtor (supondo que haja alguma), e sim identificar algum aspecto importante da contextualidade geral dos documentos para dá-lo a conhecer aos usuários, provavelmente através da descrição e, talvez, algum dia, através de arranjos virtuais alternativos (MACNEIL, 2008 apud MEEHAN, 2018, p. 322).

Neste contexto de compreender a história dos documentos, Brotham (2018) apresenta o pensamento de Nesmith (1982), segundo o qual, o argumento fundamental para a missão do arquivista é estudar e compreender a história dos documentos. Se o arquivista assumir que sua tarefa é esta, ele deve constantemente refletir sobre a prática arquivística, que é parte integrante da documentação. A história dos documentos não termina nos portais dos arquivos. Os arquivos fazem parte dessa história (NESMITH, 1982 apud BROTHAM, 2018, p. 115).

Quanto à ordem original, esta não deverá ser associada à noção de um lugar físico para cada documento dentro de uma única série de documentos, e sim vista como um reflexo lógico de múltiplas autorias e múltiplas leituras, de tal modo que, por exemplo, os dados possam ser reunidos de múltiplas maneiras, em novas "ordens" (ou "séries") conceituais ou virtuais, para diferentes transações efetuadas por diferentes produtores. Assim, um documento deverá pertencer a (ou refletir) várias séries de ordens originais, e não apenas uma (COOK, 1998, p. 60).

Portanto, a aplicação da ordem original requer uma nova interpretação, deixando o contexto em que surgem e ao qual estão submetidos os documentos, que impõem convenções ou esquemas baseados nas expectativas dos usuários ou em analogia aos documentos organizacionais. Essa nova abordagem deve focar em atender as necessidades da documentação contemporânea, fazendo a interação entre contexto, conteúdo e atividades dos acervos arquivísticos. Segundo Bucci (1992) " "é evidente que as radicais inovações na prática da arquivologia estão se tornando cada vez mais incompatíveis com a continuação de uma doutrina que procura manter-se encerrada dentro dos baluartes de seus princípios tradicionais" (BUCCI, 1992 apud COOK, 2018, p. 31).

Na procura por um respaldo teórico para sustentar a prática nesse processo de reconfiguração do acervo por representantes digitais, o enfoque adotado nesta pesquisa foi o de incentivar uma reflexão acerca da aplicabilidade dos princípios da proveniência e da ordem original na atividade arquivística contemporânea, e o contexto em que eles ocorrem e ganham forma. Esse tema deveria estar em evidência na reflexão acadêmica na área da Arquivologia, porém, estão negligenciados.

Para sintetizar os pensamentos apresentados a respeito do princípio da Ordem Original no processo de reconfiguração do acervo, elaborou-se o quadro IV, a partir das contribuições da literatura apresentada. 


\begin{tabular}{|l|l|l|}
\hline Ano & Autor & $\begin{array}{l}\text { Contribuição ao processo de reconfiguração sob o aspecto do Princípio da } \\
\text { Ordem Original }\end{array}$ \\
\hline 1998 & Cook, T. & $\begin{array}{l}\text { Considera que os dados podem ser reunidos de múltiplas maneiras, para diferentes } \\
\text { transações, efetuadas por diferentes produtores. Assim, um documento deverá } \\
\text { pertencer a (ou refletir) várias séries de ordens originais, e não apenas uma. }\end{array}$ \\
\hline 2018 & Nesmith, T. & $\begin{array}{l}\text { Estabelece que a ordem de entrada dos documentos no arquivo deve prevalecer. } \\
\text { Mas se os documentos estiverem desordenados ao serem recebidos, a ordem em } \\
\text { que serão colocados provavelmente também não será a original. }\end{array}$ \\
\hline 2018 & Meehan, J. & $\begin{array}{l}\text { Considera impossível a reconstrução da ordem original dos documentos desde sua } \\
\text { gestão, pois há diferenças entre o modo como os documentos pessoais são criados, } \\
\text { utilizados e guardados pelo produtor ("custódia pessoal"); o modo como os } \\
\text { documentos são utilizados, guardados e transmitidos por custodiantes ("história } \\
\text { custodial"); e o modo como os documentos são tratados quando confiados à } \\
\text { custódia arquivística, antes mesmo de serem formalmente processados } \\
\text { ("intervenção arquivística"). Para a autora, o atual conceito parte do particular para } \\
\text { o geral, a fim de interpretar e preservar as relações existentes entre os documentos. } \\
\text { Para equacionar a questão, ela sugere uma reconceituação da ordem original, } \\
\text { partindo do geral para o particular. }\end{array}$ \\
\hline 2018 & Brothman, B. & $\begin{array}{l}\text { Sugere que se faça uma distinção entre a Ordem Original e a ordem arquivística. O } \\
\text { processo de aplicação da ordem arquivística prática, idealizada, intelectual, cria } \\
\text { uma ordem arquivística, não uma ordem original. É preciso questionar a } \\
\text { manutenção da ordem original durante o tempo, ainda mais nos arquivos } \\
\text { modernos, em que as origens nunca são definitivas. }\end{array}$ \\
\hline
\end{tabular}

Quadro IV. Contribuições do Princípio da Ordem Original na reconfiguração do acervo. Fonte: Elaborado pelo autor (2019), com base nos autores citados.

Dessa forma, após a compreensão dos princípios arquivísticos, conseguimos identificar que os princípios da proveniência e da ordem original também estão presentes nos representantes digitais.

\section{CONSIDERAÇÕES FINAIS}

Este artigo, foi impulsionado por um sinistro ocorrido no acervo arquivístico da Seção de Memória e Arquivo busca se reconstruir por meio da reconfiguração do acervo a partir de seus representantes digitais.

No entanto, a implementação dessa reconfiguração despertou um questionamento. A constituição desse acervo digital vai respeitar os princípios basilares da Arquivística, ou seja, se nesse processo é possível verificar a proveniência e ordem original dos representantes digitais recuperados. Isso levou a um enfretamento da prática com a teoria, uma vez que a criação de acervos digitais já é uma realidade no cotidiano de muitas instituições, mas é preciso debater com a teoria arquivística essa prática.

Diante da realidade do ambiente digital, várias afirmativas da abordagem arquivística tradicional são desfeitas, pois as relações não são mais fixas, de um para um, como era entendido no relacionamento entre Proveniência e Fundo.

Tais inter-relações entre criadores, documentos e funções são baseadas em múltiplas possibilidades no seu arranjo e descrição, o que traz uma nova concepção da proveniência na constituição dos fundos, uma infinita riqueza de quase todos os tipos concebíveis de inter-relacionamentos. Essa ideia corrobora um dos pilares da reconfiguração, ou seja, a formação do acervo a partir da doação de representantes digitais por múltiplos pesquisadores.

Outra questão que merece atenção, nessa nova perspectiva, diz respeito à conceituação de Fundo segundo o princípio da proveniência, que tem como premissa ser detentor da totalidade de documentos de um produtor. Entretanto, é praticamente impossível conseguir essa totalidade, tendo em vista que documentos são destruídos, 
perdidos, transferidos ou modificados antes mesmo de chegarem aos arquivos. Sendo assim, ratifica a afirmação de Millar (2015), adotando, neste trabalho, o entendimento de que o fundo pode ser definido como resquícios e até fragmentos conservados.

Essa argumentação possibilita atribuir um sentido de fundo ao acervo que será formado pela SEMEAR, uma vez que ele será formado a partir de doações, ou seja, esses documentos serão caracterizados como vestígios, fragmentos, traços do acervo perdido.

A reconfiguração do acervo da SEMEAR também suscita um novo entendimento sobre o princípio da Ordem Original. O processo de entrada dos documentos no arquivo será realizado de forma aberta, de várias "proveniências", ou seja, por vários doadores. Sendo assim, a ordem original, nesse novo acervo, deverá ser a ordem de entrada dos documentos no arquivo.

Logo, esse entendimento rompe com a aplicação tradicional do princípio, segundo o qual o acervo deveria ser reconstituído segundo a ordem advinda do produtor. Porém, na prática isso se torna inviável, tendo em vista a incapacidade de se manter a ordem desde a gestão dos documentos. Diante dessa realidade, observa-se a necessidade de uma revisão desse conceito, podendo, sim, aceitar a ordem de entrada dos documentos no arquivo, como no caso do sinistro sofrido pela SEMEAR. Assim sendo, deve-se abarcar o reflexo lógico de múltiplas autorias e múltiplas leituras, segundo as quais, uma ordem é construída e reconstruída pelos arquivistas, não é uma ordem encontrada.

Portanto, no processo de reconfiguração proposto, é possível verificar os princípios da Proveniência e Ordem Original, mas é necessário que esses marcos teóricos sejam relidos, criticados e reapropriados, conforme as necessidades contemporâneas.

A questão que suscita o problema deste artigo é sobre se o uso de representantes digitais na criação de um acervo pode ser considerado um processo arquivístico. Essa utilização levantou uma questão sobre se essa reconfiguração com uso de representantes digitais será caracterizada como um arquivo ou uma coleção. Esse limite é muito tênue, sendo que um conjunto orgânico formado em meio digital, constituído com base em parâmetros arquivísticos, tem sim qualidades arquivísticas.

Trazendo essa percepção para o caso da reconfiguração do acervo a partir de um desastre, pode-se entender que esse acervo não é uma construção aleatória. Se fosse, isso o caracterizaria como uma coleção. Mas trata-se de um trabalho quase que arqueológico de reconstrução de acervo perdido. Dessa forma, este acervo pode obter qualidades arquivísticas, ou pelo menos busca-se resgatá-las.

Colocadas as questões que envolvem o uso de representante digitais na reconstrução de um acervo sinistrado, mas com qualidades arquivísticas, considera-se que este trabalho não teve a intenção de esgotar o debate arquivístico que a situação impõe. Ao contrário, pretende-se, com esta pesquisa, levantar a agenda de pesquisa da área, pois estas reflexões precisam ser construídas e debatidas pela comunidade arquivística do Brasil.

\section{NOTAS}

${ }^{1}$ Original: Brothman, B. 1991. Orders of value: probing the theoretical terms of archival practice. Archivaria, v. 32, p. 78-100, verão 1991.

2 O alemão Ernest Posner (1967 apud Herrera, 1991, p. 33) trabalha com outro marco, ainda na Alemanha, mais no final do século XIX, especificamente em 1881, quando Max Lehmann introduz e regula o Princípio em Berlim. Lodolini afirma que o princípio da proveniência foi aplicado pela primeira vez na Dinamarca, em 1791, e Brenneke considera Phillip Ernst Spiers precursor desse princípio, em sua obra Von Archivert, de 1777 .

3 Record group significa a "grande unidade de arquivo estabelecida de maneira arbitrária, com o devido respeito ao princípio da proveniência" (SCHELLENBERG, 2006).

4 Original em: DOUGLAS, Jennifer. Origins and beyond: The ongoing evolution of archival ideas about provenance. In: EASTWOOD, T.; MACNEIL, H. (org). Currents of Archival Thinking. Santa Barbara. ABC-CLIO. 2010, p. 25-52.

${ }^{5}$ Original: Ketelaar, Eric. Archival theory and the Dutch manual. Archivaria, v. 41, p. 31-40, primavera 1996.

6 Beattie, H. Where narratives meet: archival description provance, and women's diaries. In: Terceira conferência Internacional de História de Documentos de Arquivo, 27-29 set. 2007. Cadernos de Resumos e Anais. Boston, MA, 2007, p. 182.

7 Publicado originalmente com o título: Nesmith, T. Reopening archives: bringing new contextualities into archival theory and practice. Archivaria, v. 60 , p. $259-274$, outono 2005.

${ }^{8}$ Publicado originalmente com o título: Meehan, Jennifer. Rethinking original order and personal records. Archivaria, v. 70, p. 27-44, outono 2010.

${ }^{9}$ Original em: Bucci, Oddo (Ed.). Archival science on the threshold of the year 2000. Macerata, Italy, 1992. 


\section{REFERÊNCIAS}

BELLOTTO, H.L. Arquivos permanentes: tratamento documental. 4. ed. Rio de Janeiro: Editora FGV, 2006.

BRASIL (2005). Arquivo Nacional. Dicionário brasileiro de terminologia arquivística. Rio de Janeiro: Arquivo Nacional, 2005. 232p.; 30cm. Publicações Técnicas; $\mathrm{n}^{\mathrm{o}}$ 51. Disponível em: $<$ www.arquivonacional.gov.br/images/pdf/Dicion_Term_Arquiv.pdf $>$ [Acesso em: 13 mar. 2018]

BROTHMAN, B. Ordens de valor: questionando os termos teóricos da prática arquivística. In HEYMANN, L. NEDEL, L. (org.). Pensar os arquivos: uma antologia. Tradução de Luiz Alberto Monjardim de Calazans Barradas. Rio de Janeiro: FGV, 2018, p. 83-121.

CONARQ. NOBRADE. Norma Brasileira de Descrição Arquivística. Rio de Janeiro, Arquivo Nacional, 2006. Disponível em: <http://conarq.arquivonacional.gov.br/images/publicacoes_textos/nobrade.pdf> [Acesso em: 20 abr. 2019]

COOK, T. (1998). Arquivos pessoais e arquivos institucionais: para um entendimento comum da formação da memória em um mundo pós-moderno. Estudos Históricos, Rio de Janeiro, v. 1, n. 21, 1998. Disponível em: $<$ http://bibliotecadigital.fgv.br/ojs/index.php/reh/article/view/2062/1201> [Acesso em: 13 mar. 2018]

. (2018). O passado é prólogo: uma história das ideias arquivísticas desde 1898 e a futura mudança de paradigma. In HEYMANN, e L. NEDEL, L. (org.). Pensar os arquivos: uma antologia. Tradução de Luiz Alberto Monjardim de Calazans Barradas. Rio de Janeiro: FGV, 2018. p. 17-82.

CAMARGO, A.M. de A.e BELLOTTO, H.L. (Coord.) Dicionário de terminologia arquivística. São Paulo: Associação dos Arquivistas Brasileiros. 1996, p. 142.

CUNHA, M.B. da e CAVALCANTI, C.R. de O. Dicionário de Biblioteconomia e Arquivologia. Brasília: Briquet de Lemos, 2008.

DOLLAR, CH. M. O impacto das tecnologias de informação sobre princípios e práticas de arquivos: algumas considerações. Revista Acervo, 2012, vol. 7, nº 1-2, p. 3-38.

DOUGLAS, J. Ideias em evolução sobre o princípio da proveniência. In EASTWOOD, T. e MACNEIL, H. (org). Tradução de Anderson Bastos Martins. Revisão Técnica Heloísa Liberalli Bellotto. Correntes Atuais do Pensamento Arquivístico. Belo Horizonte. UFMG. 2016, p. 47-76.

DUCHEIN, M. O respeito aos Fundos em Arquivística: princípios teóricos e problemas práticos. Arquivo \& Administração, Rio de Janeiro, p. 14-33, abr. 1982.

Le respect des fonds en archivistique: principes théoriques et problèmes pratiques. Études d'archivistique: 1957-1992. Paris: Association des Archivistes Français, 1992, p. 9-34.

DUCROT, A. A classificação dos arquivos pessoais e familiares. Revista Estudos Históricos, 1998, vol. 11, nº 21, p. 151-168.

HORSMAN, P. (2002). The last dance of the phoenix, or the de-discovery of the Archival fonds. Archivaria: 54, 1-23.

KETELAAR, E. (Des)construir o arquivo. In HEYMANN, L. e NEDEL, L. (org.). Pensar os arquivos: uma antologia. Tradução de Luiz Alberto Monjardim de Calazans Barradas. Rio de Janeiro: FGV, 2018, p.193-206.

MEEHAN, J. Novas considerações sobre ordem original e documentos pessoais. In HEYMANN, L. e NEDEL, L. (org.). Pensar os arquivos: uma antologia. Tradução de Luiz Alberto Monjardim de Calazans Barradas. Rio de Janeiro: FGV, 2018, p. 305-328.

MILLAR, L. A morte dos fundos e a ressureição da proveniência: o contexto arquivístico no espaço e no tempo. (Traduzido pela revista). Informação Arquivística, Rio de Janeiro, vol. 4, nº 1, p. 144-162, jan./jun., 2015.

MONKS-LEESON, E. Archives on the internet: representing contexts and provenance from repository to website. The American Archivist, 2011, vol. 74, $\mathrm{n}^{\mathrm{o}}$ 1, p. 38-57. Disponível em: $<$ https://americanarchivist.org/doi/pdf/10.17723/aarc.74.1.h386n333653kr83u > [Acesso em: 22 nov. 2018]

NESMITH, T. Relendo os arquivos: novas contextualidades para a teoria e a prática arquivísticas. In HEYMANN, L. e NEDEL, L. (org.). Pensar os arquivos: uma antologia. Tradução de Luiz Alberto Monjardim de Calazans Barradas. Rio de Janeiro: FGV, 2018, p. 155-176.

RANGEL, K. da S. Revisitando o Princípio da Proveniência: percepções sobre a organicidade. 2015, 101f. Dissertação (Mestrado Profissional em Gestão de Documentos e Arquivos) - Programa de Pós-Graduação em Gestão de Documentos e Arquivos, Universidade Federal do Estado do Rio de Janeiro, Rio de Janeiro, 2015.

ROUSSEAU, J. e COUTURE, C. Os fundamentos da disciplina arquivística. Lisboa: Publicações Dom Quixote, 1998.

SOUSA, R.T.B. Os princípios arquivísticos e o conceito de classificação. In RODRIGUES, G.M. e LOPES, I.L. (org.). Organização e representação do conhecimento na perspectiva da Ciência da Informação. Brasília: Thesaurus, 2003, vol. 2, p. 240-269. 
TOGNOLI, N.B. A contribuição epistemológica canadense para a construção da Arquivística Contemporânea. 2010. 120 f. Dissertação (Mestrado em Ciência da Informação) - Faculdade de Filosofia e Ciências, Universidade Estadual Paulista, Marília (SP), 2010. 